\title{
SDG712, a Putative H3K9-Specific Methyltransferase Encoding Gene, Delays Flowering through Repressing the Expression of Florigen Genes in Rice
}

\author{
Siju Zhang, Hongjiao Hao, Xiaonan Liu, Yingying Li, Xuan Ma, Weiyin Liu, Rui Zheng, Shanshan Liang and \\ Weijiang Luan* (1)
}

\begin{abstract}
SET domain group (SDG) proteins have been identified to be involved in histone modification and participate in diverse biological processes. Rice contains 41 SDG genes, however, most of which have not been functionally characterized. Here, we report the identification and functional investigation of rice SDG712 gene. Phylogenic analysis revealed that SDG712 belongs to the H3K9-specific SDG subclade. SDG712 is highly expressed in leaves during reproductive growth stage with obvious circadian rhythmic pattern. Mutation of SDG712 promotes rice flowering, while overexpression of SDG712 delays rice flowering. Gene expression analysis suggested that SDG712 acts downstream of Hd1, while acts upstream of Ehd1, Hd3a and RFT1. Subcellular localization assay demonstrated that SDG712 is localized in the nucleus. Chromatin immunoprecipitation (ChIP) assay showed that the H3K9me2 levels at Hd3a and RFT1 loci were increased in SDG712 overexpression transgenic plants, indicating that SDG712 may mediate the H3K9 di-methylation on these loci to repress rice flowering. Taken together, our findings demonstrated that SDG712 is a negative flowering regulatory gene in rice, and it delays flowering through repressing key flowering regulator gene Ehd1 and the florigen genes Hd3a and RFT1.
\end{abstract}

Keywords: Rice, SDG712, Flowering, Histone methyltransferase, Florigen

\section{Background}

Rice is an important food crop worldwide, which supplies more than half of the world's population. Rice yield is restricted by various environmental factors, including photoperiod, temperature, nutrition, etc. Heading-date (or flowering time) is an important agronomic trait closely related to rice yield and regional adaptability; it is mainly modulated by photoperiodic signals and endogenous flowering regulatory genes. Rice is a facultative short-day (SD) plant, short-day induces the flowering while long-day (LD) represses the flowering. In the past decades, with the development of molecular genetics,

\footnotetext{
* Correspondence: Iwjzsq@163.com

College of Life Sciences, Tianjin Key Laboratory of Animal and Plant Resistance, Tianjin Normal University, Tianjin 300387, China
}

several key genes have been identified to play important roles in photoperiodic flowering regulatory pathways in rice. Hd3a and RFT1 are two important promoting genes of rice flowering (Komiya et al., 2008). They encode the florigens, a kind of small globular protein, synthesized in leaves, and transported into shoot apical meristem (SAM) cells, to promote rice flowering under SD and LD conditions, respectively. In SAM cells, florigens bind with 14-3-3 and OsFD1 protein, forming the florigen activation complex (FAC). Then, FAC binds to the promoter of floral identity genes, such as MADS14 and MADS15, to induce the floral initiation (Taoka et al., 2011, 2013).

The expression of florigen genes are mainly regulated by several critical genes under SD and LD conditions.

\section{Springer Open}

() The Author(s). 2021 Open Access This article is licensed under a Creative Commons Attribution 4.0 International License, which permits use, sharing, adaptation, distribution and reproduction in any medium or format, as long as you give appropriate credit to the original author(s) and the source, provide a link to the Creative Commons licence, and indicate if changes were made. The images or other third party material in this article are included in the article's Creative Commons licence, unless indicated otherwise in a credit line to the material. If material is not included in the article's Creative Commons licence and your intended use is not permitted by statutory regulation or exceeds the permitted use, you will need to obtain permission directly from the copyright holder. To view a copy of this licence, visit http://creativecommons.org/licenses/by/4.0/. 
Under SD condition, $H d 1$ encodes a zinc finger protein and acts as the upstream regulator to positively regulate the expression of florigen gene $\mathrm{Hd} 3 \mathrm{a}$ (Yano et al., 2000). Ehd1 encodes a B-type response regulator and upregulates the expression of $H d 3 a$ to promote rice flowering under SD condition (Doi et al., 2004). Under LD condition, on the one hand, $H d 3 a$ was repressed by $H d 1$ which serves dual functions with promoting rice flowering under $\mathrm{SD}$ and inhibiting rice flowering under $\mathrm{LD}$ conditions. On the other hand, Ghd7 acts as a key repressor of $\mathrm{Hd} 3 \mathrm{a}$ to inhibit rice flowering under LD condition (Xue et al., 2008; Zheng et al., 2019). Recent studies showed that DTH8 encodes the HAP3 subunit of HF-YB protein and interacts with Hd1 and Ghd7 to repress the expression of $\mathrm{Hd} 3 \mathrm{a}$ by the formation of Hd1DTH8-Ghd7 complex (Cai et al., 2019; Wei et al., 2010). When the expression of $H d 3 a$ is repressed, RFT1 serves as the major florigen gene to promote rice flowering under LD condition. RFT1 is induced by Ehd1 and DTH2 under LD condition (Komiya et al., 2008; Wu et al., 2013). Ehd1 was negatively regulated by $H d 1$, Ghd7, DTH8 and DTH7, and positively regulated by Ehd2, Ehd4 and Ehd3 (Xue et al., 2008; Wei et al., 2010; Gao et al., 2014; Matsubara et al., 2008, 2011; Gao et al., 2013).

In recent years, epigenetic regulation was reported to play important roles in plant growth and development (Jacob et al., 2009; Guo et al., 2010; Sui et al., 2012). In eukaryotic cells, lysine residues (K) of histone H3 subunit were prone to be acetylated or methylated. Acetylation of lysine residues generally promotes gene transcription, while methylation of different lysine residues has diversified effects (Thorstensen et al., 2011). In general, methylation of $\mathrm{H} 3 \mathrm{~K} 4$ and $\mathrm{H} 3 \mathrm{~K} 36$ promotes gene expression, while methylation of H3K9 and H3K27 represses gene expression (Thorstensen et al., 2011). The methylation process of lysine residues on $\mathrm{H} 3$ is conducted by histone methyltransferases (HMTase), and the methylation activity of HMTase is site-specific. The SET domain group (SDG) genes were identified to perform the activity of HMTase (Ng et al., 2007). Several SDGs were reported to be involved in the photoperiodic flowering pathways. In Arabidopsis, AtSDG25 and AtSDG26 both encode H3K4/H3K36-specific HMTases. AtSDG25 represses flowering by activating the expression of FLOWERING LOCUS C, and AtSDG26 promotes flowering by binding at SOC1 locus (Berr et al., 2009, 2015). AtSDG27 encodes a H3K4-specific HMTase and is involved in mediating the H3K4 tri-methylation at $F L O W$ ERING LOCUS C locus (Pien et al., 2008). AtSDG8 encodes a H3K36-specific HMTase involving in H3K36 di-methylation at FLOWERING LOCUS C (Zhao et al., 2005). In rice, SDG701 and SDG723 encode H3K4specific HMTases, promoting flowering by enhancing the expression of florigen genes and Ehd3 (Choi et al., 2014, Liu et al., 2017). SDG723 also mediates the H3K4 tri-methylation at Ehd1 locus by interacting with OsWD5a and SIP1 (Jiang et al., 2018a, b). SDG708, SDG724 and SDG725 encode H3K36-specific HMTases and promote rice flowering by inducing the expression of Ehd1, Hd3a and RFT1 gene under SD and LD conditions (Sun et al., 2012; Sui et al., 2013; Liu et al., 2016). SDG711 and SDG718 both encode H3K27-specific HMTases to repress the expression of OsLF gene (a repressor of $H d 1$ ). SDG711 delays flowering under LD condition, and SDG718 promotes flowering under SD condition (Liu et al., 2014).

Rice genome contains 41 SDGs, most of which have not been functionally characterized, and no H3K9specific $S D G s$ have been reported to be involved in flowering regulation in rice (Shi et al., 2015). Here, we report that SDG712 is a putative H3K9-specific HMTase encoding gene and is a negative regulator of rice flowering. Loss of function of SDG712 promotes flowering while overexpression of SDG712 inhibits rice flowering. The key flowering regulatory gene Ehd 1 and florigen genes $H d 3 a$ and RFT1 are down-regulated in SDG712 overexpression transgenic lines, suggesting that SDG712 delays rice flowering through repressing key flowering regulator Ehd1 and the florigen genes Hd3a and RFT1.

\section{Results}

\section{SDG712 Is a Putative H3K9-Specific methyltransferase}

In our previous studies, we identified a photoperiodinsensitive mutant $h d 1-3$, in which $H d 1$ gene was functionally deficient due to several deletions/insertions (Luan et al., 2009). To identify novel genes involved in flowering regulation, we performed microarray analysis to screen for the up- and down-regulated genes affected by $H d 1$ mutation. The majority of genes do not have significantly differential expressions between the wild-type and the $h d 1-3$ mutant under either SD or LD condition (red bracket in Supplemental Fig. 1A). We identified 264 genes that showed above 2-fold expression changes in both SD and LD conditions (Supplemental Table 1). Gene ontology analysis of these 264 genes showed that they were enriched in protein kinase, protein modification and degradation, and phosphorylation processes (Supplemental Fig. 1B). Among them, 44 genes have above 5-fold changes in both LD and SD conditions (Supplemental Fig. 1C). We focused on the gene LOC_Os02g40770 (red asterisk in Supplemental Fig. 1C), which encodes a putative methyltransferase and was designated as SDG712 in a previous phylogenetic study (Ng et al., 2007). qRT-PCR assay confirmed that the expression of SDG712 was significantly decreased in $h d 1-3$ mutant compared with wild type under both SD and LD conditions (Fig. 1A, B), in agreement with the microarray result. 

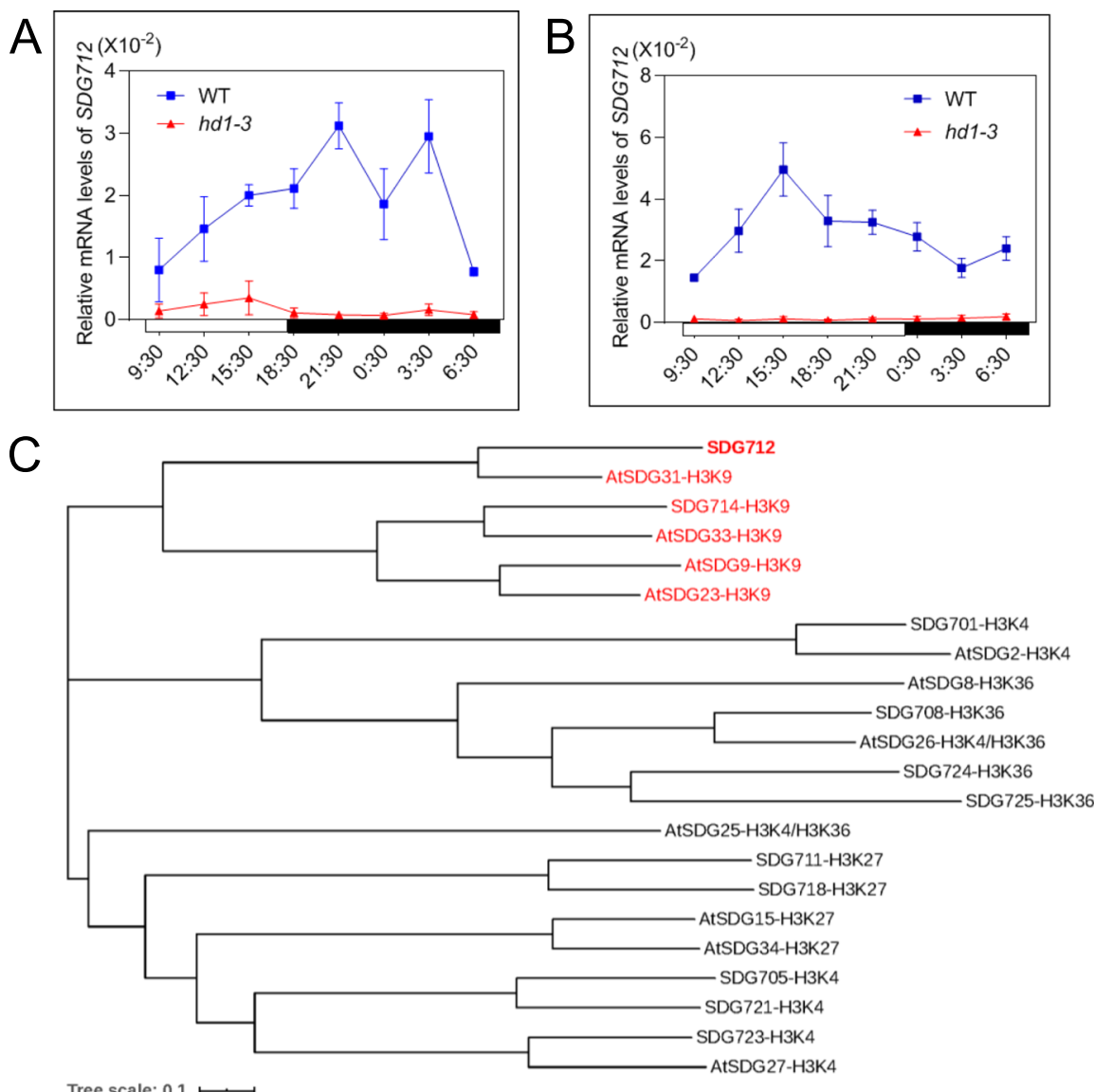

\begin{tabular}{lll|l|l}
\hline & Pre-SET & SET & Post-SET \\
\hline
\end{tabular}

\section{E Pre-SET}

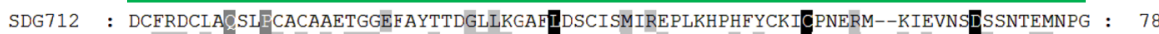
SDG714 : CDDISGGODNLIPATNLVDDPPVPPT-GFVYSKSIKIPKGIKIPSYCNGCDCEGDOANNKN--CSCAOPNGSDLPYVSH : 77 AtSDG9 : NVDITEGKRTLPICAVNNLDDE-KPPP--FIYTAKMIYP-DWCRPIPPKSCGCTNGOSKSKN--CACIVKNGGKIPY--- : 71 AtSDG23 : KLDISEGKEQSEISAVNEIDDE-KPPL--ETYTVKI IYP-DWCRPVPPKSCCCTTROTEAEARVCACVEKNGGEIPYN-- : 74 AtSDG31 : NCKGNCLSADFPCTCARETSGEYAYTKEGLLKEKHIDTCLKMKKEPDSF PKVYCKDOP-------LERDHDKG----TYG : 69 AtSDG33 : CEDISGGLEFKGIFATRVDDSPVSPTSGETYIKSIIIEPNVIIPKSSTGCNCRGSTTDSKKK--CACAKINGGNFPVDL : 78

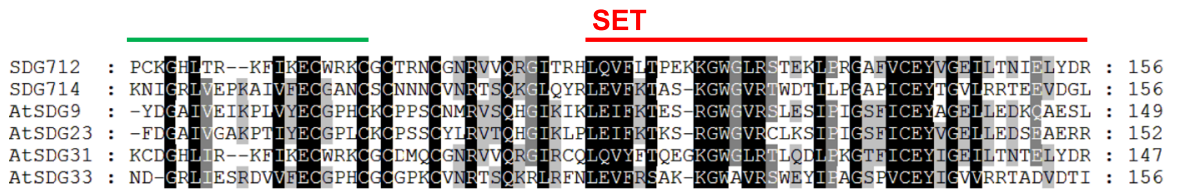

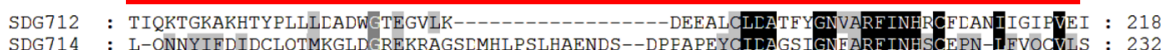
SDG714 : L-QNNYIFDIDCLQTMKGLDGREKRAGSLMHLPSLHAENDS--DPFAPEYGILAGSIGNFARE INHSGEPN-IFVQVVLS : 232 AtSDG23:- IGNDEYLFDIGNRYDNSIAQGMMSEIML-----GTCAGRSMAEGDESSGETILAASKGNVGREINHSOSPN-IYAQNVLY: 225 AtSDG23 : IGNDEYLFDIGNRYDNSLAQGMSELML----GTCAGRSMAEGDESSGEIILAASKGNVGRE INHSGSPN-LYAQNVLY: 225 AtSDG33 : S-DNEYIFEIDCQQTMQGLGERQRRLR-DVAVFMNNGVSQSSEDENAPEFCILAGSTGNFAREINHSGEPN-IFVQCVLS: 233

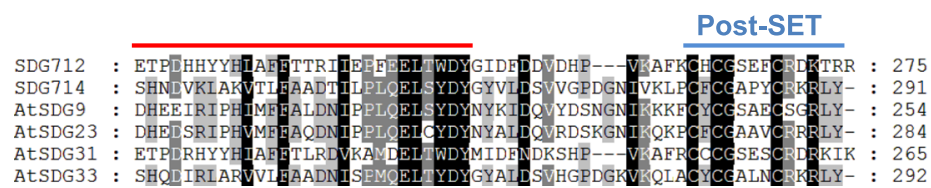

Fig. 1 (See legend on next page.) 
(See figure on previous page.)

Fig. 1 Identification and phylogenic analysis of SDG712. A and B, Relative expression levels of SDG712 in Zhonghua11 and hd1-3 under short-day (SD) and long-day (LD) conditions, respectively. WT, Zhonghua11. White boxes indicate light-period, and filled boxes indicate dark-period. C, Phylogenic analysis of SDG712 and functionally characterized SDGs in Arabidopsis and rice using MEGA-X. The Genebank accession numbers for the peptide sequences of SDGs are NP_193253.4 (AtSDG2), NP_177854.6 (AtSDG8), NP_001324386.1 (AtSDG9), NP_001078559.1 (AtSDG15), NP_850030.1 (AtSDG23), NP_001318731.1 (AtSDG25), NP_177797.2 (AtSDG26), NP_850170.1 (AtSDG27), NP_187088.2 (AtSDG31), NP_196900.1 (AtSDG33), NP_197821.1 (AtSDG34), XP_015649923.1 (SDG701), XP_015621708.1 (SDG705), XP_015633505.1 (SDG708), XP_015644234.1 (SDG711), XP_015623394.1 (SDG712), XP_015629359.1 (SDG714), XP_015630972.1 (SDG718), XP_015611850.1 (SDG721), XP_015612383.1 (SDG723), XP_015651319.1 (SDG724), and XP_015625429.1 (SDG725). D, The common motifs of characterized H3K9-specific SDGs and SDG712. Pre-SET, SET and Post-SET denote three conserved domains in SDG families. E, Amino acids sequence alignment of SDG712 and characterized H3K9-specific SDGs in conserved Pre-SET, SET and Post-SET domains

BLAST analysis showed that SDG712 belongs to the histone methyltransferase protein family containing SET domain. Phylogenic analysis of SDG712 and several functionally characterized SDGs in rice and Arabidopsis showed that SDG712 was grouped into H3K9-specific subclade (Fig. 1C). This subclade also includes Arabidopsis AtSDG9, AtSDG23, AtSDG31, AtSDG33 and rice SDG714 (Veiseth et al., 2011; Ebbs and Bender, 2006; Ding et al., 2007). The closest homolog of SDG712 in Arabidopsis is AtSDG31, which converts H3K9me1 to H3K9me3 on transposon chromatin in Arabidopsis (Veiseth et al., 2011). The H3K9-specific subclade members contain a common classic SET domain that is featured by Pre-SET, SET and Post-SET domains (Ng et al., 2007; Ding et al., 2007) (Fig. 1D). These SDGs shows high similarity among the three domain (Fig. 1E), indicating that they may have common catalytic activity.

\section{SDG712 Displays High Expression in Leaves during the Reproductive Growth Stage}

To investigate the temporal and spatial expression pattern of SDG712, wild type Zhonghua11 plants were grown in paddy field and various tissues were collected for qRT-PCR assay. The results showed that SDG712 was expressed in all tissues examined, including roots, culms, sheaths, panicles and shoot apical meristems (SAMs), especially highly expressed in leaves (Fig. 2A).
We further examined the expression levels of SDG712 in leaves at different growth stages. The result showed that SDG712 displays lower expression in the vegetative growth stage. SDG712 exhibits higher expression during the transition phase from vegetative growth to reproductive growth (Fig. 2B), then maintains higher expression after flowering, especially during the ripening stages. Furthermore, we investigated the diurnal expression rhythm of SDG712 in leaves in 24 h cycle under SD and LD conditions. The results showed that SDG712 exhibits diurnal expression rhythm with the peak at daytime under LD condition and the peak at dark under SD condition (Fig. 2C), and the expression under LD condition is slightly higher than that under SD condition.

\section{Loss of Function of SDG712 Promotes Heading-Date in Rice}

To investigate the phenotype of loss of function of SDG712, we obtained a SDG712 Tos17-insertion line, NG0566, from the rice mutant library (http://tos.nias. affrc.go.jp) (Miyao et al., 2007), which was generated in the japonica variety Nipponbare. In NG0566, a 4000 bp Tos17 fragment was inserted into the fourth exon of SDG712 (Fig. 3A), resulting in the loss of function of SDG712. Therefore, we termed NG0566 as $s d g 712$. We further identified the homozygous $s d g 712$ mutant by triprimer PCR and found that wild type plants can only
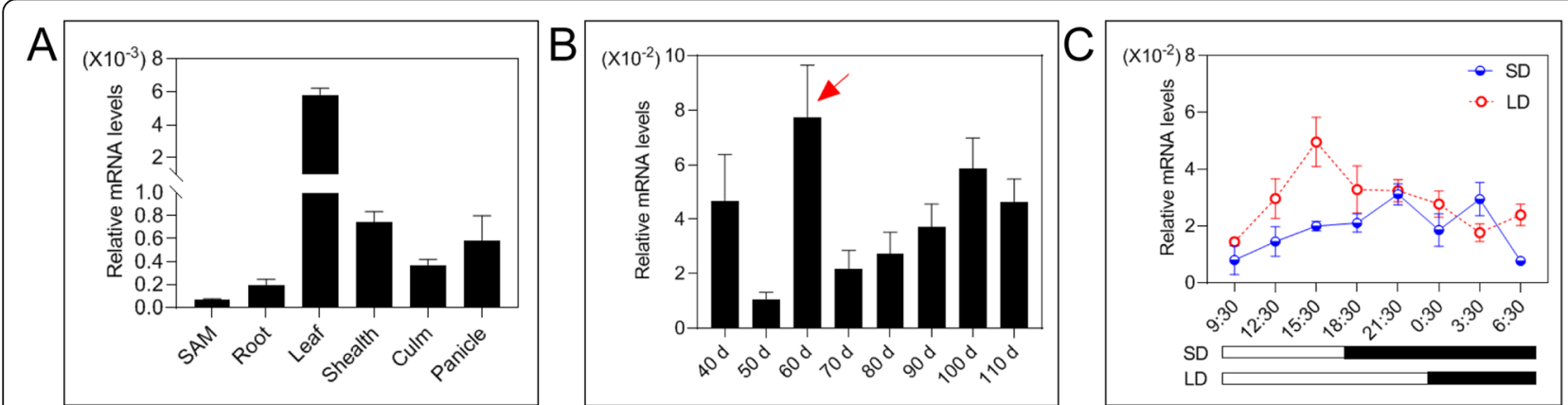

Fig. 2 Spatial and temporal expression analysis of SDG712 gene. A, The expression of SDG712 in various tissues. B, The expression of SDG712 at different growing stages. Arrow head indicates the transition stage from vegetative growth to reproductive growth. $\mathbf{C}$, The diurnal expression pattern of SDG712 under short-day and long-day conditions. SD, short-day condition; LD, long-day condition. White boxes indicate light-period, and filled boxes indicate dark-period 

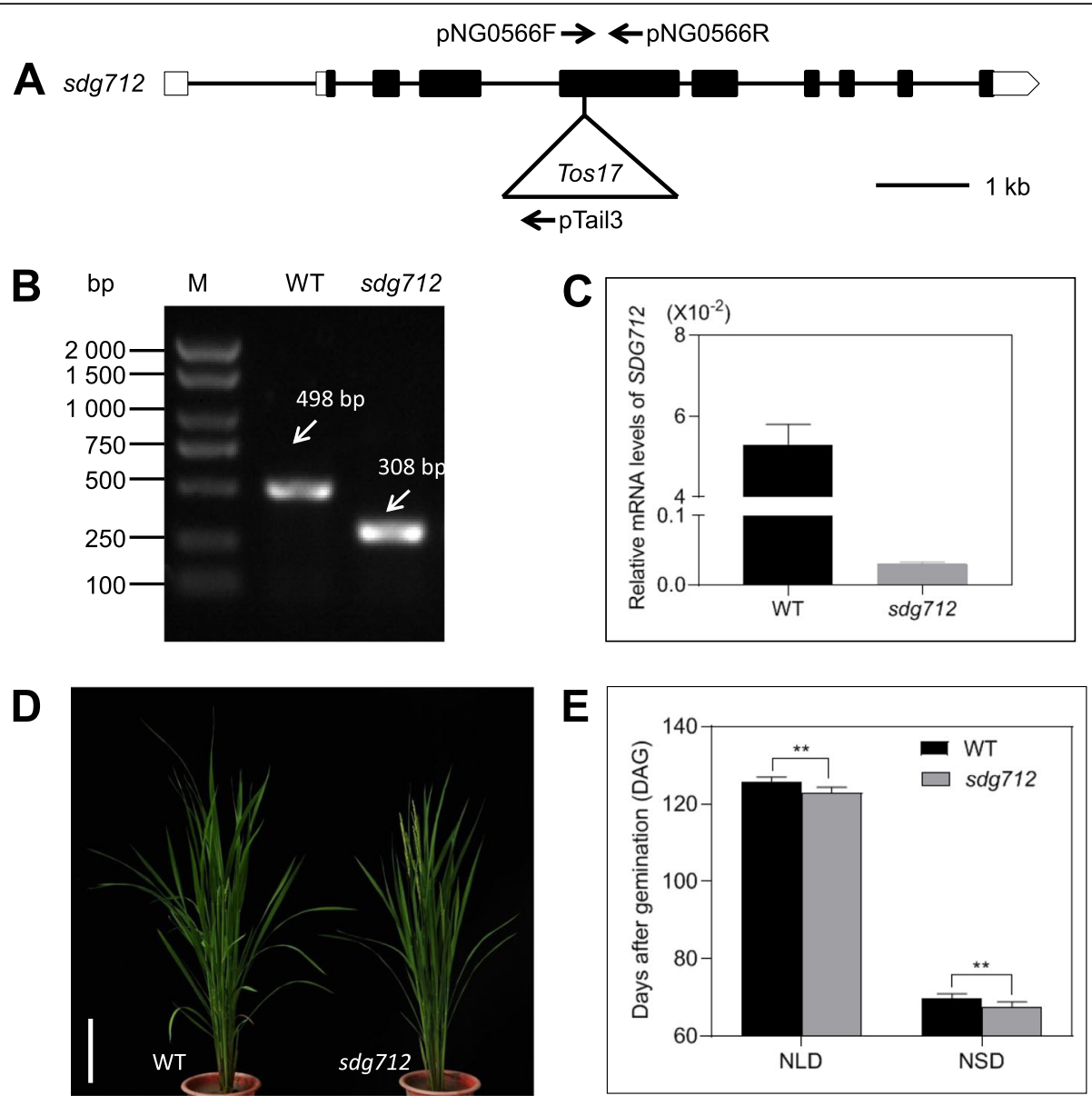

Fig. 3 Identification and phenotypic analysis of sdg712. A, Schematic of Tos 17 insertion site in sdg712 mutant. Open boxes denote $5^{\prime} U T R$ and 3'UTR; filled boxes denote exons. Lines are introns, and arrows denote primers of detection. B, Identification of homozygous sdg712 mutant using primers pNG0566F, pNG0566R and pTail3 (indicated by arrows in A). Primers pNG0566F and pNG0566R are located in the fourth exon of sdg712 and pTail3 is located in the left border of Tos 17. M, DNA ladder. WT is Nipponbare. C, The expression of SDG712 in sdg712 mutant and WT Nipponbare. OsActin 1 was used as internal control. D, The phenotype of $s d g 712$ under natural long-day condition. Bar $=20 \mathrm{~cm}$. WT is Nipponbare. E, Heading-date of sdg712 under natural long-day (NLD) and natural short-day (NSD) conditions. Values are shown as means \pm SD. N $\geq 30$ individual plants. WT is Nipponbare. Asterisks indicate statistically significant differences of t-test $(* *, P<0.01)$

amplify a 498 bp band by gene-specific primers, whereas homozygous sdg712 mutants can only obtain a $308 \mathrm{bp}$ band by the primer of Tos 17 border and gene-specific primer (Fig. 3A, B), suggesting that Tos 17 fragment indeed inserts into $S D G 712$. We also examined the transcript level of $S D G 712$ in $s d g 712$ mutant by qRT-PCR. The results showed that the expression of SDG712 was almost undetectable in the $s d g 712$ mutant (Fig. 3C), indicating that the Tos 17 insertion not only changed the reading-frame of $S D G 712$ but also reduced the transcript level of $S D G 712$, thus $s d g 712$ is certainly a loss of function mutant.

To investigate the phenotype of $s d g 712$ mutant, $s d g 712$ homozygous mutant and the wild type Nipponbare were grown in Tianjin $\left(117^{\circ} \mathrm{E}, 39^{\circ} \mathrm{N}\right.$; natural long-day condition, $\mathrm{NLD})$ and Lingshui, Hainan province $\left(110^{\circ} \mathrm{E}, 18^{\circ} \mathrm{N}\right.$; natural short-day condition, NSD) for heading-date observation.
For plants grown in Tianjin, the $s d g 712$ plants flowered at 123 days after germination (DAG), while the wild type Nipponbare flowered at 126 DAG (Fig. 3D-E). For plants grown in Lingshui, the $s d g 712$ plants flowered at 68 DAG, while the wild type Nipponbare flowered at 70 DAG (Fig. $3 \mathrm{E})$. These data showed that the loss of function of $S D G 712$ promotes rice heading, indicating that SDG712 is a negative regulator of heading-date. In addition, agronomic traits including plant height, panicle length, grain numbers per panicle, and 1000-grain weight were also investigated in NLD fields of Tianjin, no significant difference between the wild type and the mutant was observed (Supplemental Fig. 2).

\section{Overexpression of SDG712 Delays Heading-Date in Rice} In order to investigate the biological function of $S D G 712$, we constructed an overexpression vector with 
double CaMV 35S promoter to drive SDG712 expression and obtained transgenic plants via Agrobacterium-mediated transformation method (Fig. 4A). Four independent transgenic lines were generated. Two independent transgenic lines were planted to produce homozygous $T_{2}$ generation plants. qRT-PCR detection showed that SDG712 expression levels of the two transgenic lines were significantly elevated compared with wild type plants (Fig. 4B), suggesting that overexpression vector worked well. Phenotypic observation found that the two transgenic lines both displayed a delayed heading-date phenotype in field (Fig. 4C-D). The heading-date of transgenic lines delayed about a week compared with the wild type Zhonghua11 under NLD condition in Tianjin $\left(117^{\circ} \mathrm{E}, 39^{\circ} \mathrm{N}\right)$ and NSD condition in Lingshui $\left(110^{\circ} \mathrm{E}, 18^{\circ} \mathrm{N}\right)$ (Fig. 4D). We also investigated several other agronomic traits of the wild type Zhonghua11 and
SDG712-overexpression transgenic lines (SDG712-OX lines) in NLD fields of Tianjin, however, no significant difference was observed (Supplemental Fig. 2), demonstrating that SDG712 may play roles only in heading-date regulation. Furthermore, we also investigated the heading-date of the wild type and the transgenic plants under artificial day-length conditions with $9 \mathrm{~h}$ light/ $15 \mathrm{~h}$ dark for SD condition and $15 \mathrm{~h}$ light/9 h dark for LD conditions. Under artificial SD condition, the heading-date of wild type was 111 DAG and that of SDG712-OX1 was 119 DAG. Under artificial LD condition, the heading-date of wild type was 123 DAG and that of SDG712-OX1 was 134 DAG (Fig. 4E). This result is in agreement with the result under NLD and NSD conditions, indicating that overexpression of SDG712 represses rice flowering regardless of day-length conditions.
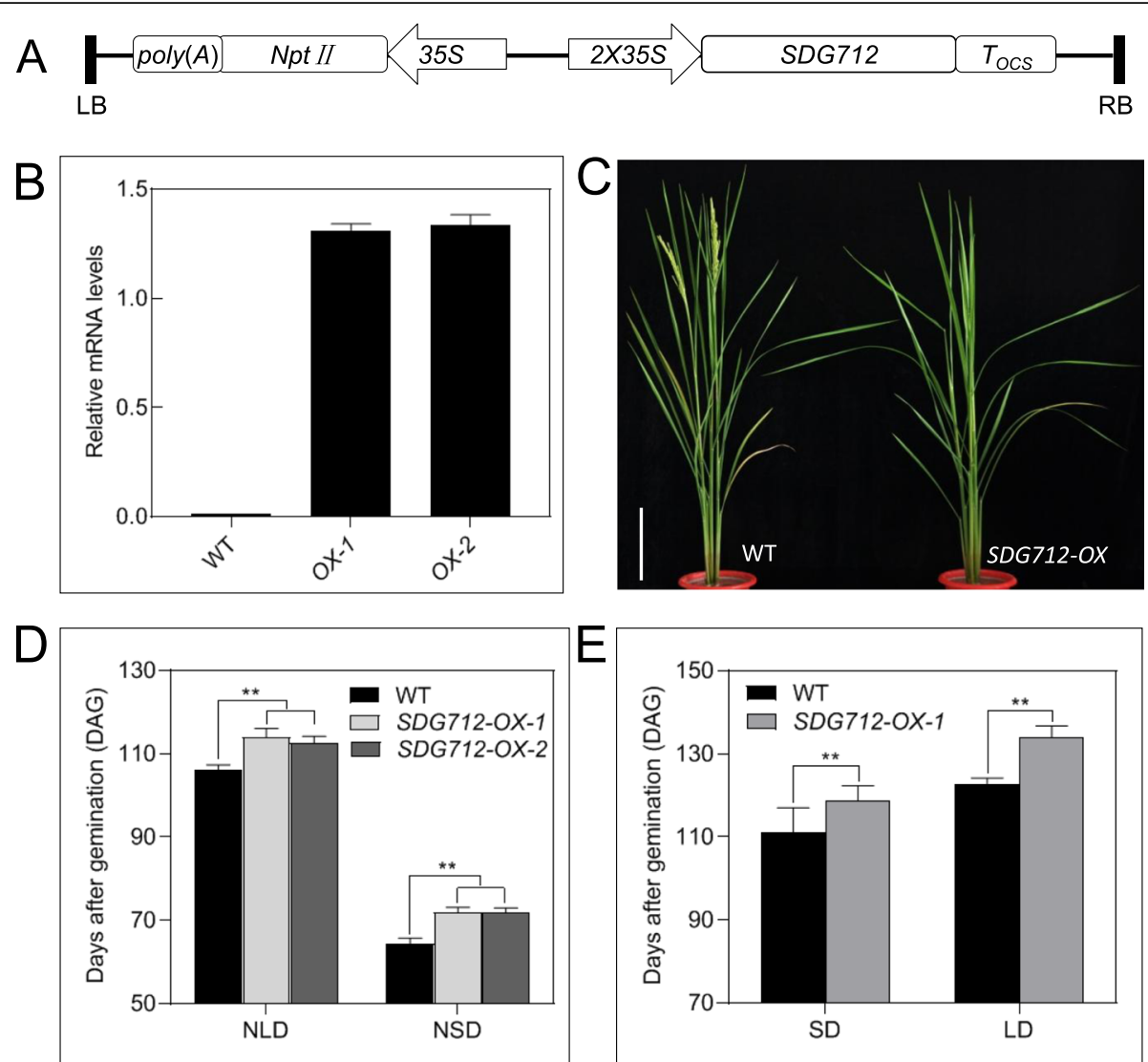

Fig. 4 Obtainment and phenotypic analysis of SDG712 overexpression transgenic lines. A, Structure of the vector used for overexpression of SDG712. 35S, 2X35S, Cauliflower Mosaic Virus (CaMV) 35 S promoter sequences; Nptll, neomycin phosphotransferase II gene; TOCS, terminator of octopine synthase gene; RB, right border; LB, left border. B, Expression of SDG712 in transgenic plants overexpressing SDG712 (SDG712-OX) by qRT-PCR. WT, Zhonghua11; OX-1, OX-2, transgenic lines. C, The phenotype of SDG712-OX under natural long-day condition. Bar $=20 \mathrm{~cm}$. D, Heading-date of SDG712-OX lines under natural long-day (NLD) and natural short-day (NSD) conditions. Values are shown as means \pm SD. N $\geq 30$ individual plants. E, Heading-date of SDG712-OX-1 plants under artificial day-length conditions. The wild type Zhonghua11 and SDG712-OX1 transgenic plants were grown in Tianjin. Two-week-old plants were subjected to light-controlled treatments with $9 \mathrm{~h}$ light/ 15 dark for SD condition and $15 \mathrm{~h}$ light/9 $\mathrm{h}$ dark for LD condition. The heading-date was recorded after heading. Values are shown as means \pm SD. $N \geq 20$ individual plants. SD, artificial short-day condition; LD, artificial long-day condition. Asterisks in (D) and (E) indicate statistically significant differences of t-test $(* *, P<0.01)$ 
SDG712 Delays Rice Flowering through Inhibiting the Expression of Florigen Genes Hd3a and RFT1

Given the change of rice flowering time in SDG712 overexpression transgenic lines and $s d g 712$ mutant, we speculated that SDG712 may affect the expression of genes involved in photoperiodic flowering pathway. To reveal the molecular mechanism of SDG712, we investigated the regulatory relationship between $S D G 712$ and several key genes of photoperiodic flowering pathway. Firstly, expression of $S D G 712$ was significantly reduced in $h d 1-$ 3 mutant under both SD and LD conditions, suggesting that $H d 1$ acts as the upstream regulator to positively regulate the expression of SDG712 (Fig. 1A, B). Then, we examined the expressions of several key flowering regulatory genes in SDG712-OX lines and the wild type Zhonghua11. The results showed that the expressions of Ehd1, Hd3a, RFT1 and MADS14 were significantly down-regulated in SDG712-OX lines under both shortday and long-day conditions (Fig. 5 and Fig. 6), while the expressions of other flowering regulatory genes, including OsMADS50, Ehd2, Ehd3, Ehd4, DTH7, DTH8, Ghd7 and $H d 1$, were not significantly changed between SDG712-OX lines and the wild type (Supplemental Fig. 3 and Supplemental Fig. 4). These results indicated that $S D G 712$ gene functions downstream of $H d 1$, while upstream of key regulator $E h d 1$ and the florigen genes.

\section{SDG712 Protein Is Localized in the Nucleus}

Since SDG712 encodes a putative H3K9-specific HMTase, which may functions in histone methylation, we speculated that the SDG712 protein should be localized in the nucleus. To test this, we carried out subcellular localization assay of SDG712 protein. The recombinant vector expressing CaMV35S::SDG712:GFP was transiently expressed in tobacco, with the empty vector expressing CaMV35S::GFP served as control. The results showed that GFP signal was exclusively observed in the nucleus in the epidermal cell of tobacco with recombinant vector, while GFP signal was observed ubiquitously in the cell in the control with empty vector (Fig. 7), suggesting that SDG712 protein is exclusively localized in the nucleus and thus may play roles in the nucleus.

\section{The H3K9me2 Levels of Hd3a and RFT1 Loci Were Increased in SDG712 Overexpression Transgenic Plants} Given that SDG712 encodes putative H3K9-specific histone methyltransferase and negatively regulates the expression of the downstream Ehd1 and the florigen genes $H d 3 a$ and RFT1, we further performed ChIP assay to examine the methylation level of Ehd1, Hd3a and RFT1 loci. The previous studies have shown that H3K9specific methyltransferase mainly exhibits H3K9me2
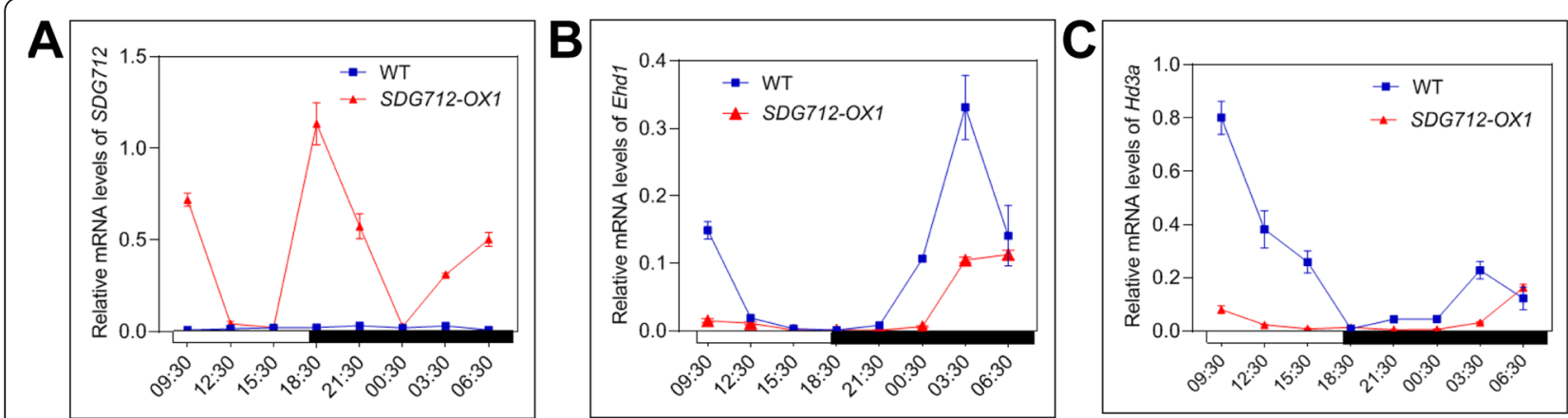

D

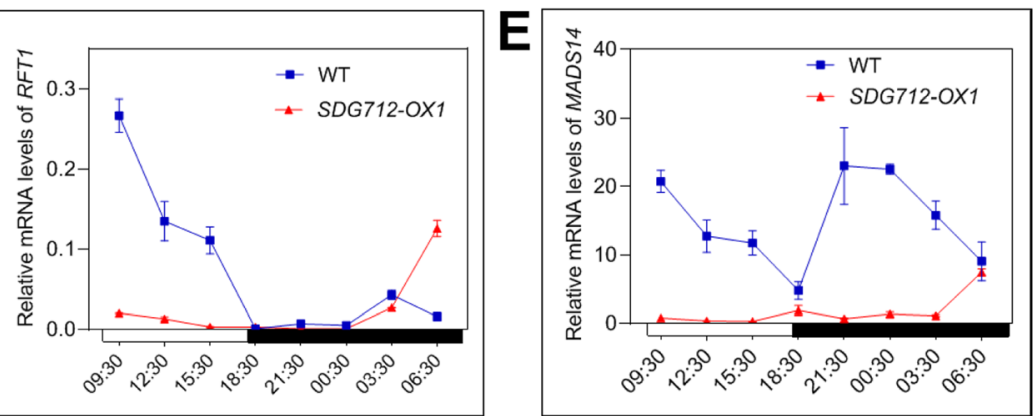

Fig. 5 Gene expression under short-day (SD) condition. Plants were grown in artificial climate cabinets under SD condition with $9 \mathrm{~h}$ light/15 h dark at $28^{\circ} \mathrm{C}$. Penultimate leaves were collected for RNA extraction every $3 \mathrm{~h}$ within $24 \mathrm{~h}$ from 50-day-old plants. OsActin 1 gene was used as internal control. WT, Zhonghua11. A, Transcript levels of SDG712 in WT and SDG712-OX1 plants. B-E, the expression of Ehd1, Hd3a, RFT1 and MADS14 in WT and SDG712-OX1 plants. Open boxes denote light-period and filled boxes denote dark-period 


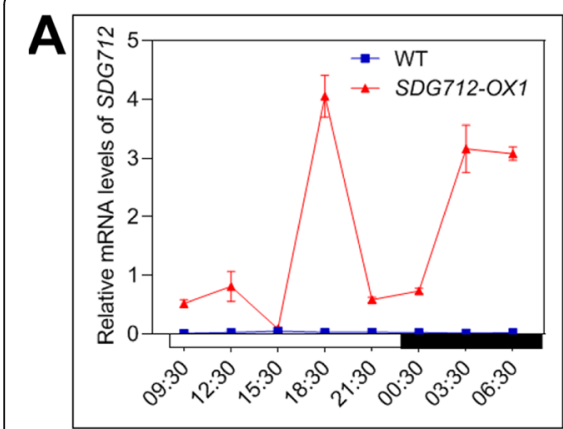

B

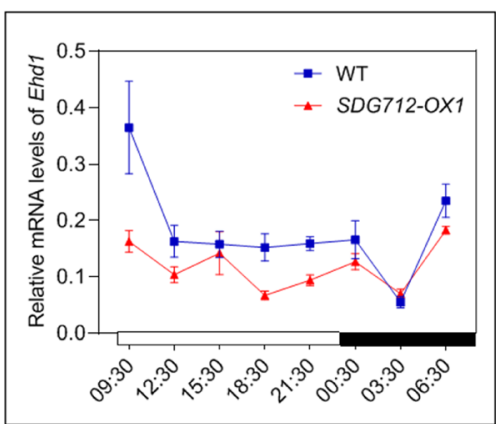

D

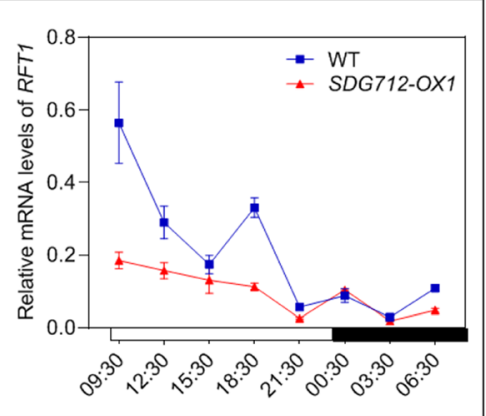

\section{E}

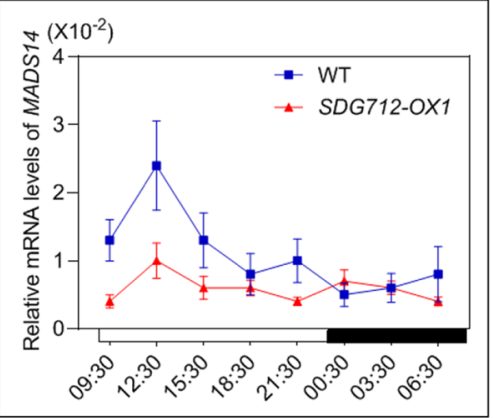

C

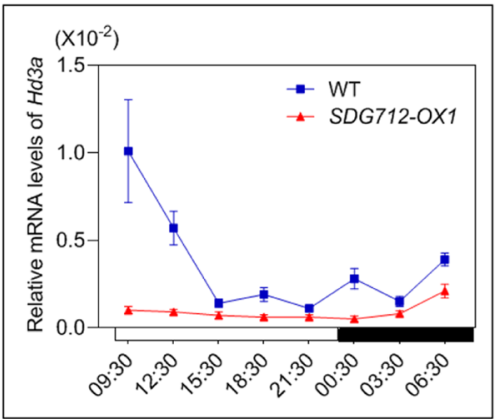

Fig. 6 Gene expression under long-day (LD) condition. Plants were grown in artificial climate cabinets under LD condition with $15 \mathrm{~h}$ light/9 h dark at $28{ }^{\circ} \mathrm{C}$. Penultimate leaves were collected for RNA extraction every $3 \mathrm{~h}$ within $24 \mathrm{~h}$ from 50 -day-old plants. OsActin 1 gene was used as internal control. WT, Zhonghua11. A, Transcript levels of SDG712 in WT and SDG712-OX1 plants. B-E, The expression of Ehd1, Hd3a, RFT1 and MADS14 in WT and SDG712-OX1 plants. Open boxes denote light-period and filled boxes denote dark-period

activity (Ding et al., 2007), therefore, we examined the H3K9me2 levels at these loci. 10 primer sets in Ehd1, 8 primer sets in RFT1 and 6 primer sets in $H d 3 a$ were designed to perform ChIP qRT-PCR to analyze the change of histone methylation level (Fig. 8A). The result demonstrated that H3K9me2 levels at $H d 3 a$ and RFT1 loci were significantly increased in the SDG712-OX1 plants compared with wild type plants (Fig. 8C-D), indicating that overexpression of SDG712 increased H3K9me2 levels at $H d 3 a$ and RFT1 loci. No obvious changes of H3K9me2 level at Ehd1 locus were detected between SDG712-OX1 plants and wild type plants (Fig. 8B), even though Ehd1 expression was significantly downregulated in SDG712-OX1 plants compared with wild type plants (Fig. $5 \mathrm{C}$ and Fig. $6 \mathrm{C}$ ). Taken together, these results suggested that SDG712 may mediate the H3K9
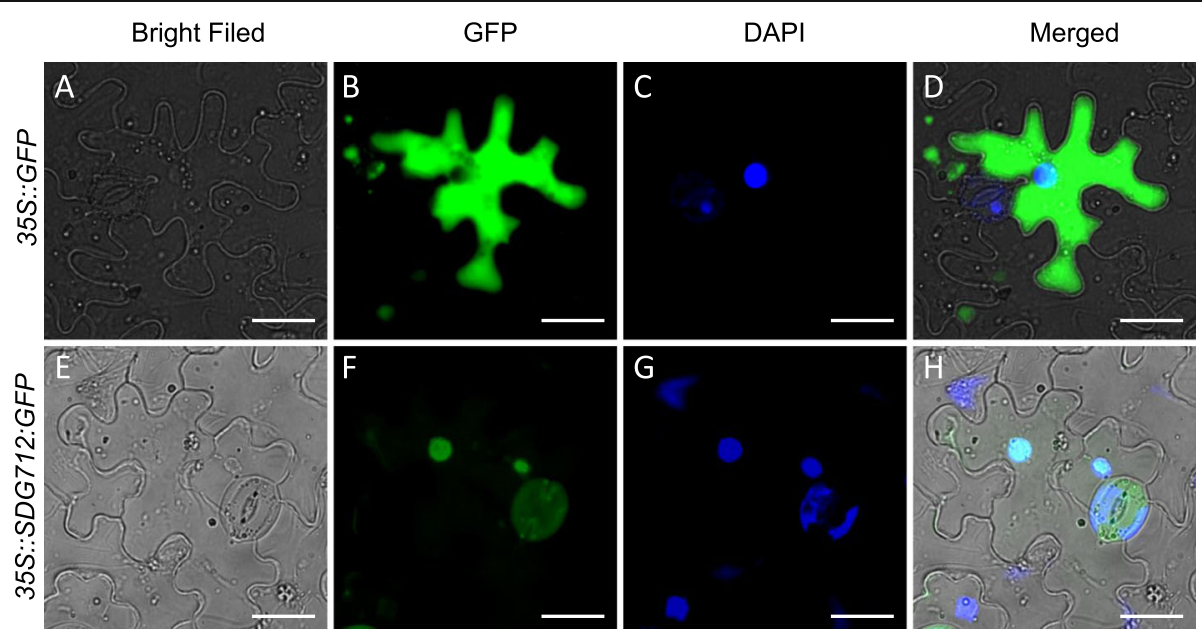

Fig. 7 Subcellular localization assay of SDG712 protein. A-D, The transient expression of pCAMBIA35S::GFP empty vector in tobacco epidermal cells. $\mathbf{E}-\mathbf{H}$, The transient expression of pCAMBIA35S::SDG712:GFP fusion vector in tobacco epidermal cells. Bars $=25 \mu \mathrm{m}$ 


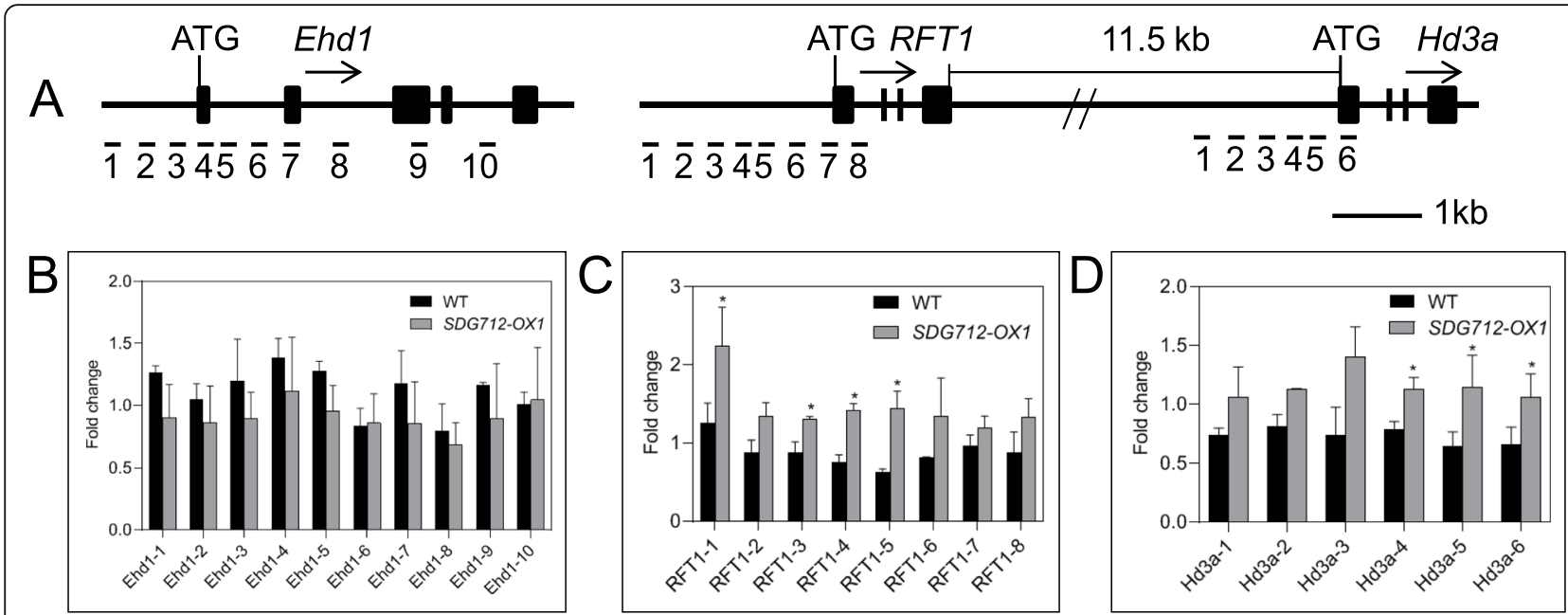

Fig. 8 Chromatin immunoprecipitation qPCR (ChIP-qPCR) assays of Ehd1, RFT1 and Hd3a loci. Leaves of 50-day-old plants grown in fields were collected $3 \mathrm{~h}$ after dawn. ChIP assays were performed using antibodies against histone H3K9 dimethylation (H3K9me2), and gPCR (Quantitative PCR) was used to analyze the levels of methylation of Ehd1, RFT1 and Hd3a. A, the structure of Ehd1, RFT1 and Hd3a. Filled boxes denote exons and lines denote introns or $5^{\prime}$ upstream regions of corresponding genes. Arrows denote the transcription direction of genes. The numbers 1-10 denote the position of primers. B-D, qPCR results of Ehd1, RFT1 and Hd3a loci, respectively. OsActin1 was used as an internal standard for normalization. WT, Zhonghua11. Three biological replicates were performed. Asterisks indicate statistically significant differences of t-test $\left({ }^{*}, P<0.05\right)$

di-methylation at RFT1 and $H d 3 a$ loci, but not at Ehd1 locus.

\section{Discussion}

SDGs play important roles in various cellular activities, and regulate plant growth and development. In this study, we identified a histone methyltransferase encoding gene SDG712 and found that it negatively regulates rice flowering. Loss of function of $S D G 712$ promotes rice flowering, while overexpression of SDG712 inhibits rice flowering. Gene expression analysis revealed that the expression of Ehd 1 and the florigen genes $H d 3 a$ and RFT1 were down-regulated in SDG712-OX plants, resulting in the down-regulation of floral identity gene MADS14. Based on these results, we conclude that SDG712 is involved in the classical photoperiodic flowering regulatory pathway Ehd1-Hd3a/RFT1-MADS14/15 to regulate rice flowering. In addition, our results showed that $H d 1$ functions upstream of $S D G 712$ and positively regulates expression of SDG712 under SD and LD conditions. Moreover, SDG712-OX lines and $s d g 712$ mutant has delayed and earlier heading-date, respectively. These results are consistent with the expression patterns of $H d 1$ and SDG712, which display diurnal expression under SD and LD condition. According to the previous studies, $\mathrm{Hd} 3 \mathrm{a}$ is the major florigen under SD condition and RFT1 is the major florigen under LD condition (Komiya et al., 2008), therefore, we propose that the delay of rice flowering under SD condition is mainly controlled by the Hd1-SDG712-Ehd1-Hd3a-MADS14/15 pathway, and under LD condition, it is mainly controlled by $H d 1$ SDG712-Ehd1-RFT1-MADS14/15 pathway (Fig. 9).

Our ChIP-qPCR assay showed that H3K9me2 levels at $H d 3 a$ and RFT1 loci were increased, indicating that SDG712 inhibits rice flowering through increasing H3K9me2 deposition at Hd3a and RFT1. Interestingly, H3K9me2 level at Ehd1 locus was not significantly changed, even though the expression of Ehd1 was downregulated in SDG712-OX plants, suggesting that the reduced expression of Ehd1 may be caused by other mechanism rather than chromatin modification. This result is similar to other $S D G$ members in previous studies. For example, SDG724 encodes a H3K36-specific HMTase, the transcript level of $E h d 1$ was reduced in $s d g 724$ mutant, but the H3K36me2/3 levels of Ehd1 were not significantly changed (Sun et al., 2012). SDG701 encodes a H3K4specific HMTase, the transcript level of Ehd1 was reduced in sdg701-1 mutant, but the H3K4me3 levels of Ehd1 were not significantly changed (Liu et al., 2017). We propose that $S D G 712$ can also regulate rice flowering by directly increasing H3K9me2 levels at $H d 3 a$ and RFT1 besides the classical photoperiodic flowering regulatory pathway (Fig. 9).

In previous studies, several SDGs not only regulated flowering time but also changed the leaf emergence rate or other traits in Arabidopsis (Saleh et al., 2008; Tamada et al., 2009). In this study, except heading date, other agronomic traits were not significant difference between wild type and $s d g 712$ mutant and SDG712-OX lines, indicating that SDG712 gene mainly affecting rice flowering time. 


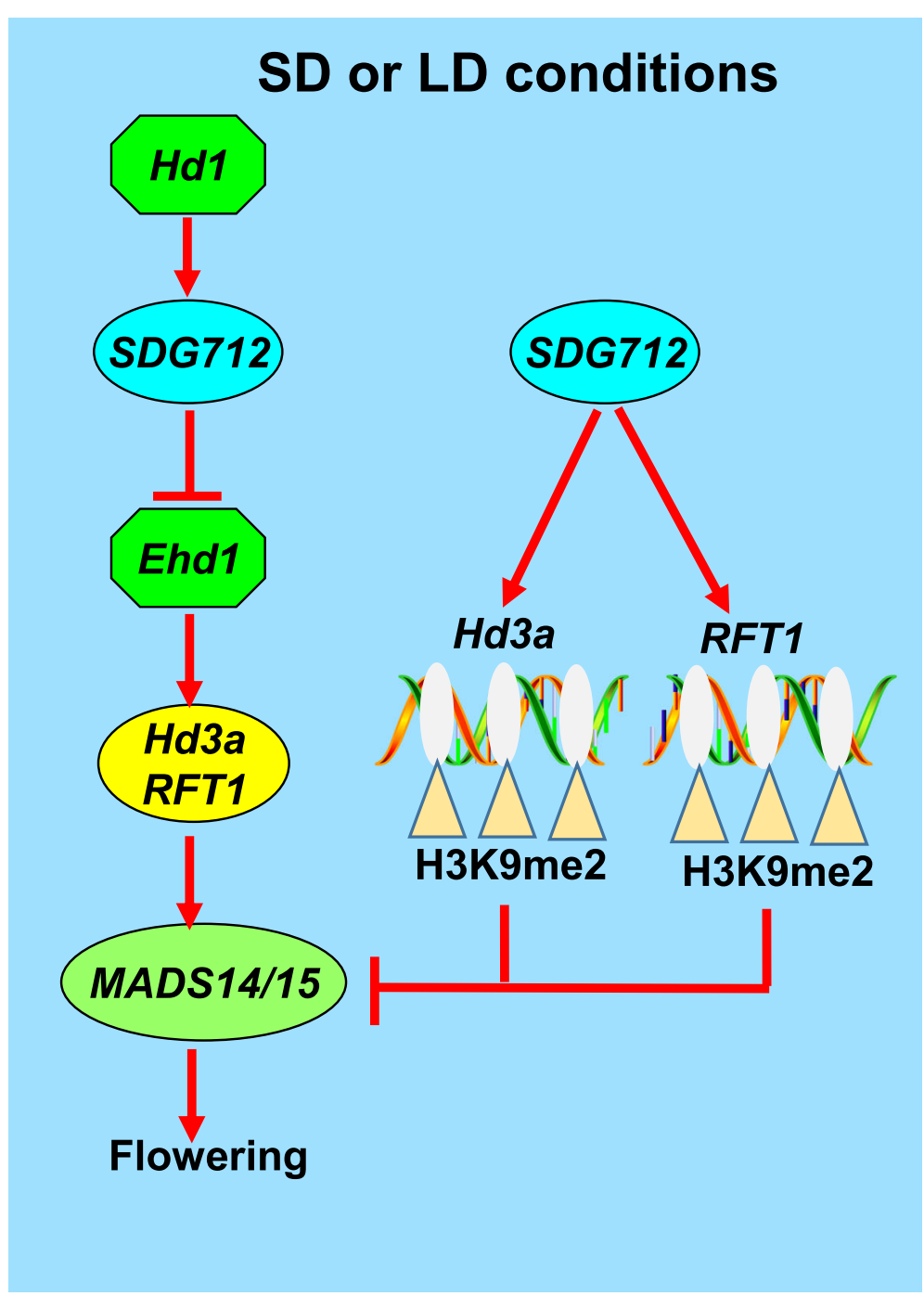

Fig. 9 Proposed working model of SDG712 in rice flowering. SDG712 negatively regulates rice flowering by two possible pathways. In one pathway, SDG712 represses the expression of Ehd1, thus represses the expression of downstream florigen genes Hd3a and RFT1 to delay rice flowering. In the other pathway, SDG712 represses the expression of Hd3a and RFT1 genes directly by mediating the H3K9 di-methylation (H3K9me2) at these two loci to delay rice flowering

SDGs play important roles in epigenetic regulation of rice flowering. Several different types of SDGs were reported to be involved in this course. H3K4-specific methyltransferase (SDG701 and SDG723) and H3K36specific methyltransferases (SDG708, SDG724 and SDG725) mainly promote rice flowering, while H3K27specific methyltransferases (SDG711) delays rice flowering (Choi et al., 2014, Liu et al., 2017; Sun et al., 2012; Sui et al., 2013; Liu et al., 2016; Liu et al., 2014). Here, we reported that SDG712, an H3K9-specific methyltransferase, can also delay rice flowering. Based on these studies, SDGs display a complex pattern of epigenetic regulation in rice flowering. In our study, the effects of epigenetic regulation of SDG712 on rice flowering are relatively weak, since $s d g 712$ mutants was preceded only
2-3 days under NSD and NLD conditions. It is possible that there may be other unknown H3K9-specific SDG homologs that redundantly regulate rice flowering. There are 15 members of putative H3K9-specific SDGs in rice ( $\mathrm{Ng}$ et al., 2007); however, the function of the rest 13 members remains unclear. On the other hand, different types of SDGs (H3K4, H3K9, H3K27, H3K36specific HMTases) may share the same regulatory pathways in flowering to fine-tune the flowering time and to finally fulfill the dynamic balance each other. In addition, beyond SDGs, other genes involved in the process of chromatin modification could also affect the expression of flowering regulatory genes. OsVIL2 is a plant homeodomain (PHD) containing chromatin remodeling factor, it functions together with PRC2 to mediate the H3K27 
tri-methylation at OsLFL1 gene (a repressor of Ehd1), thus repressing the OsLFL1 expression, resulted in promoted rice flowering (Yang et al., 2013). OsVIL3, a homolog of OsVIL2, binds to the promoter region of OsLF (a repressor of $H d 1$ ) and represses the OsLF expression via H3K27 tri-methylation, promoting rice flowering under SD condition (Wang et al., 2013). These studies support the notion that in rice flowering is epigenetically regulated and involves complex gene regulatory networks.

\section{Conclusion}

In this study, we identified $S D G 712$ as a negative regulator of rice heading-date. Mutation of SDG712 promoted rice flowering, overexpression of $S D G 712$ delayed rice flowering. SDG712 acts downstream of $H d 1$, while upstream of florigen gene $H d 3 a$ and RFT1. The dimethylation of H3K9 at Hd3a and RFT1 loci were increased in SDG712 overexpression plants, demonstrating that SDG712 mediated the H3K9 methylation of the florigen genes. The findings in this study provide an understanding of SDG member's function.

\section{Materials and Methods}

\section{Plant Materials}

The wild type Nipponbare and $s d g 712$ mutants; as well as the wild type Zhonghua11 and SDG712 overexpression transgenic lines were grown in the fields in Tianjin, China $\left(117^{\circ} \mathrm{E}, 39^{\circ} \mathrm{N}\right.$; natural long-day condition, NLD) and Lingshui, Hainan province, China $\left(110^{\circ} \mathrm{E}, 18^{\circ} \mathrm{N}\right.$; natural short-day condition, NSD) for phenotypic investigation. Plants for diurnal gene expression analysis were grown in artificial climate cabinets with day length $9 \mathrm{~h}$ light $/ 15 \mathrm{~h}$ dark for short-day condition and $15 \mathrm{~h}$ light/9 $\mathrm{h}$ dark for long-day condition at $28^{\circ} \mathrm{C}$.

\section{Affymetrix GeneChip Analysis}

Affymetrix Rice Genome Array was used in gene expression analysis. Biotinylated RNAs were prepared according to the standard Affymetrix protocol (Affymetrix, Inc. USA). Affymetrix GenChip hybridization, washing, staining, and scanning were carried out according to manufacturer's instructions. GeneChips were scanned using Affymetrix Scanner 3000 with default settings. The microarray data were analyzed using Molecule Annotation System (MAS 5.0) algorithm. Microarray data has been deposited in NCBI GEO database under the accession number of GSE166053.

\section{Characterization of the sdg712 Mutant}

To obtain SDG712 knockout mutants, we searched the Rice Tos17 Insertion Mutant Database (https://tos.nias. affrc.go.jp/) and screened the line NG0566, in which the Tos17 fragment was inserted into the fourth exon of
SDG712 gene. We acquired the NG0566 line and characterized it by tri-primer PCR using Tos 17 specific primer pTail3 and SDG712 gene specific primers pNG0566-F and pNG0566-R (Supplemental Table 2).

\section{The Obtainment of Transgenic Plants Overexpressing SDG712}

For overexpression of SDG712, coding sequence was amplified from the total cDNA of Zhonghual1 with primers pSDG712-OX-F and pSDG712-OX-R (Supplemental Table 2), and then cloned into binary vector pCAMBIA2300 with double CaMV35S promoter. The recombinant vector was transformed into Agrobacterium strain EHA105 via electroporation transformation method. Subsequently, the transgenic plants were obtained using the Agrobacterium-mediated transformation method described by Hiei (Hiei et al., 1994).

\section{Gene Expression Analysis}

Sample collections of gene expression analysis are as follows: (1) For spatial and temporal expression analyses, the wild type Zhonghual1 plants were grown in the paddy field under natural long-day condition. Various tissues were collected at 10 a.m. at different developmental stages: SAMs were collected from 8-day-old plants; leaves, sheaths and roots were collected from 50-day-old plants; panicles were collected from reproductive stage plants. (2) For expression analysis at different growth stages, Zhonghua11 plants were grown in the paddy field under natural long-day condition, penultimate leaves were collected in the morning at $10 \mathrm{a} . \mathrm{m}$. every 10 days from the beginning of 40-day-old Zhonghua11 plants. (3) For diurnal expression analyses, rice plants were grown in artificial climate cabinets under SD condition with $9 \mathrm{~h}$ light $/ 15 \mathrm{~h}$ dark at $28^{\circ} \mathrm{C}$ and under $\mathrm{LD}$ condition with $15 \mathrm{~h}$ light $/ 9 \mathrm{~h}$ dark at $28^{\circ} \mathrm{C}$. Penultimate leaves of 50-day-old plants were collected for RNA extraction every $3 \mathrm{~h}$ within $24 \mathrm{~h}$ cycle. Three biological replicates were performed.

For all gene expression analysis, total RNAs were extracted using Trizol solution (Invitrogen, USA). cDNAs were synthesized from $1 \mu \mathrm{g}$ of total RNA. One micro liter of cDNA was used for real-time PCR analysis using SYBR Green PCR master mix (Vazyme biotech, China) and the gene specific primer pairs (Supplemental Table 2). Realtime PCR was performed in a LightCycler 480 system (Roche, USA). OsActin1 gene was used as an internal control. Data were analyzed by the LightCycler480 Software system according to the instruction manual. Relative expression levels were calculated following $2^{-\Delta \Delta C t}$ method described previously (Livak and Schmittgen, 2001).

\section{Subcellular Localization}

The cDNA sequence of SDG712 without stop codon was cloned and ligated into the empty vector p35S::GFP to 
produce the recombinant plasmid p35S::SDG712:GFP. Then, p35S::SDG712:GFP was introduced into Agrobacterium strain and infiltrated into tobacco leaves. $72 \mathrm{~h}$ after infiltration, the GFP signals in epidermal cell layers were observed under fluorescence microscope (Leica, DM5000B, Germany), and images were captured.

\section{Chromatin Immunoprecipitation Experiments}

Chromatin immunoprecipitation (ChIP) experiments were performed using 50-day-old rice plants grown in paddy field under natural LD condition. The experiment was performed according to the method described previously (Weng et al., 2018). Antibodies against H3K9me2 was purchased from Abcam (Cat no. ab1220). Quantitative real-time PCR was carried out to determine the enrichment of DNA immunoprecipitated in the ChIP experiments, using gene-specific primers of $E h d 1, H d 3 a$ and RFT1 (Supplemental Table 2; Liu et al., 2017). OsActin1 was used as internal control.

\section{Abbreviations}

ChIP: Chromatin immunoprecipitation; DAG: Days after germination; FAC: Florigen activation complex; HMTase: Histone methyltransferases; LD: Long-day condition; NLD: Natural long-day condition; NSD: Natural shortday condition; SAM: Shoot apical meristem; SD: Short-day condition; SDG: SET Domain group

\section{Supplementary Information}

The online version contains supplementary material available at https://doi. org/10.1186/s12284-021-00513-9.

Additional file 1: Supplemental Fig. 1. Microarray gene expression analysis of hd1-3. (A) Global gene expression changes in the mutant hd1-3 compared with the wild-type. Each row represents a rice gene. Red bracket indicate large amounts of genes have slight expression changes. The $\log _{2}$ (hd1-3/WT) value is presented in color scale. LD, longday; SD, short-day. (B) Gene ontology analysis of the genes having 2-fold change under both LD and SD conditions. (C) 44 genes show $>5$-fold changes under both LD and SD conditions. The red asterisk indicates SDG712 (LOC_Os02g40770). Supplemental Fig. 2. Agronomic traits of $s d g 712$ and the overexpression lines under natural long-day condition. ZH11, Zhonghua11; NIP, Nipponbare. $N \geq 30$. Supplemental Fig. 3. Gene expression analysis under short-day (SD) condition. Plants were grown in artificial climate cabinets under SD condition with $9 \mathrm{~h}$ light/15 h dark at $28^{\circ} \mathrm{C}$. Penultimate leaves were collected for RNA extraction every $3 \mathrm{~h}$ within $24 \mathrm{~h}$ from 50-day-old plants. OsActin 1 gene was used as internal control. WT, Zhonghua11. Open boxes denote light-period and filled boxes denote dark-period. Supplemental Fig. 4. Gene expression analysis under short-day (LD) condition. Plants were grown in artificial climate cabinets under SD condition with $9 \mathrm{~h}$ light/15 h dark at $28^{\circ} \mathrm{C}$. Penultimate leaves were collected for RNA extraction every $3 \mathrm{~h}$ within $24 \mathrm{~h}$ from 50-day-old plants. OsActin1 gene was used as internal control. WT, Zhonghua11. Open boxes denote light-period and filled boxes denote dark-period.

Additional file 2: Supplemental Table 1. Global gene expressions in wild-type rice and hd1-3 mutant.

Additional file 3: Supplemental Table 2. Primers used for vector construction and gene expression analysis.

\section{Acknowledgements}

We are grateful to Dr. Xian Deng from Institute of Genetics and Developmental Biology, Chinese Academy of Sciences for help in experiment.

\section{Authors' Contributions}

SJZ and WJL designed the experiments and wrote the manuscript. SJZ, HJH, $X N L, Y Y L, R Z$ and WJL performed all of the experiments, analyzed the data, with the assistance of XM and SSL. All authors read and approved the final manuscript.

\section{Funding}

This work was supported by the National Nature Science Foundation of China (Grant No. 31770343), the Tianjin Natural Science Foundation of China (Grant No. 17JCYBJC30000), and the Tianjin Rice Industrial Technology System of China (Grant No. ITTRRS2018006).

\section{Availability of Data and Materials}

The datasets supporting the conclusions of this article are included within the article and its additional files.

\section{Declarations}

Ethics Approval and Consent to Participate

Not applicable.

\section{Consent for Publication}

Not applicable.

\section{Competing Interests}

The authors declare that there are no conflicts of interest.

Received: 6 December 2020 Accepted: 16 July 2021

Published online: 06 August 2021

\section{References}

Berr A, Shafiq S, Pinon V, Dong A, Shen W (2015) The trxG family histone methyltransferase SET DOMAIN GROUP 26 promotes flowering via a distinctive genetic pathway. Plant Physiol 81:316-328

Berr A, Xu L, Gao J, Cognat V, Steinmetz A, Dong A, Shen W (2009) SET DOMAIN GROUP25 encodes a histone methyltransferase and is involved in FLOWERING LOCUS C activation and repression of flowering. Plant Physiol 151(3):14761485. https://doi.org/10.1104/pp.109.143941

Choi SC, Lee S, Kim S, Lee Y, Liu C, Cao X, An G (2014) Trithorax group protein Oryza sativa Trithorax 1 controls flowering time in rice via interaction with early heading date3. Plant Physiol 164(3):1326-1337. https://doi.org/10.1104/ pp.113.228049

Ding Y, Wang X, Su L, Zhai J, Cao S, Zhang D, Liu CY, Bi YP, Qian Q, Cheng ZK, Chu CC, Cao XF (2007) SDG714, a histone H3K9 methyltransferase, is involved in Tos17 DNA methylation and transposition in rice. Plant Cell 19(1):9-22. https://doi.org/10.1105/tpc.106.048124

Doi K, Izawa T, Fuse T, Yamanouchi U, Kubo T, Shimatani Z, Yano M, Yashimura A (2004) Ehd1, a B-type response regulator in rice, confers short-day promotion of flowering and controls FT-like gene expression independently of Hd1. Genes Dev 18(8):926-936. https://doi.org/10.1101/gad.1189604

Gao H, Jin M, Zheng X, Chen J, Yuan D, Xin Y, Wang M, Huang D, Zhang Z, Zhou K, Sheng P, Ma J, Ma W, Deng H, Jiang L, Liu S, Wang H, Wu C, Yuan L, Wan J (2014) Days to heading 7, a major quantitative locus determining photoperiod sensitivity and regional adaptation in rice. Proc Natl Acad Sci U S A 111(46):16337-16342. https://doi.org/10.1073/pnas.1418204111

Gao H, Zheng X, Fei G, Chen J, Jin M, Ren Y, Wu W, Zhou K, Sheng P, Zhou F, Jiang L, Wang J, Zhang X, Guo X, Wang JL, Cheng Z, Wu C, Wang H, Wan JM (2013) Ehd4 encodes a novel and Oryza-genus-specific regulator of photoperiodic flowering in rice. PLoS Genet 9(2):e1003281. https://doi.org/1 0.1371/journal.pgen.1003281

Guo L, Yu Y, Law JA, Zhang X (2010) SET DOMAIN GROUP2 is the major histone H3 lysine 4 trimethyltransferase in Arabidopsis. Proc Natl Acad Sci U S A 107(43):18557-18562. https://doi.org/10.1073/pnas.1010478107

Hiei Y, Ohta S, Komari T, Kumashiro T (1994) Efficient transformation of rice (Oryza sativa L.) mediated by agrobacterium and sequence analysis of the boundaries of the T-DNA. Plant J 6(2):271-282. https://doi.org/10.1046/j.13 65-313X.1994.6020271.X

Jacob Y, Feng S, Leblanc CA, Bernatavichute YV, Stroud H, Cokus S, Johnson LM Pellegrini M, Jacobsen SE, Michaels SD (2009) ATXR5 and ATXR6 are H3K27 monomethyltransferases required for chromatin structure and gene silencing. Nat Struct Mol Biol 16(7):763-768. https://doi.org/10.1038/nsmb.1611 
Jiang P, Wang S, Jiang H, Cheng B, Wu K, Ding Y (2018a) The COMPASS-like complex promotes flowering and panicle branching in rice. Plant Physiol 176(4):2761-2771. https://doi.org/10.1104/pp.17.01749

Jiang P, Wang S, Zheng H, Li H, Zhang F, Su Y, Xu Z, Lin H, Qian Q, Ding Y (2018b) SIP1 participates in regulation of flowering time in rice by recruiting OsTrx1 to Ehd1. New Phytol 219(1):422-435. https://doi.org/10.1111/nph.15122

Komiya R, Ikegami A, Tamaki S, Yokoi S, Shimamoto K (2008) Hd3a and RFT1 are essential for flowering in rice. Development 135(4):767-774. https://doi.org/1 $0.1242 /$ dev.008631

Liu B, Wei G, Shi J, Jin J, Shen T, Ni T, Shen WH, Yu Y, Dong A (2016) SET DOMAIN GROUP 708, a histone H3 lysine 36-specific methyltransferase, controls flowering time in rice (Oryza sativa). New Phytol 210(2):577-588. https://doi.org/10.1111/nph.13768

Liu K, Yu Y, Dong A, Shen WH (2017) SET DOMAIN GROUP701 encodes a H3K4methytransferase and regulates multiple key processes of rice plant development. New Phytol 215(2):609-623. https://doi.org/10.1111/nph.14596

Liu X, Zhou C, Zhao Y, Zhou S, Wang W, Zhou DX (2014) The rice enhancer of zeste $[E(z)]$ genes $S D G 711$ and $S D G 718$ are respectively involved in long day and short day signaling to mediate the accurate photoperiod control of flowering time. Front Plant Sci 5:591

Livak KJ, Schmittgen TD (2001) Analysis of relative gene expression data using real-time quantitative PCR and the $2^{-\Delta \Delta C}$ T. Method 25(4):402-408. https://doi. org/10.1006/meth.2001.1262

Luan W, Chen H, Fu Y, Si H, Peng W, Song S, Liu W, Hu G, Sun Z, Xie D, Sun C (2009) The effect of the crosstalk between photoperiod and temperature on the heading-date in rice. PLoS One 4(6):e5891. https://doi.org/10.1371/journa I.pone.0005891

Matsubara K, Yamanouchi U, Nonoue Y, Sugimoto K, Wang Z, Minobe Y, Yano M (2011) Ehd3, encoding a plant homeodomain finger-containing protein , is a critical promoter of rice flowering. Plant J 66(4):603-612. https://doi.org/1 0.1111/j.1365-313X.2011.04517.x

Matsubara K, Yamanouchi U, Wang Z, Minobe Y, Izawa T, Yano M (2008) Ehd2, a rice ortholog of the Maize INDETERMINATE1 gene, promotes flowering by upregulating Ehd1. Plant Physiol 148(3):1425-1435. https://doi.org/10.1104/pp.1 08.125542

Miyao A, Iwasaki Y, Kitano H, Itoh Jl, Maekawa M, Murata K, Yatou O, Nagato Y, Hirochika H (2007) A large-scale collection of phenotypic data describing an insertional mutant population to facilitate functional analysis of rice genes. Plant Mol Biol 63(5):625-635. https://doi.org/10.1007/s11103-006-9118-7

Ng DW-K, Wang T, Chandrasekharan MB, Aramayo R, Kertbundit S, Hall TC (2007) Plant SET domain-containing proteins : Structure, function and regulation. Biochim Biophys Acta 1769(5-6):316-329. https://doi.org/10.1016/j.bbaexp.2 007.04 .003

Pien S, Fleury D, Mylne JS, Crevillen P, Inze D, Avramova Z, Dean C, Grossniklaus U (2008) ARABIDOPSIS TRITHORAX1 dynamically regulates FLOWERING LOCUS C activation via histone 3 lysine 4 trimethylation. Plant Cell 20(3):580-588. https://doi.org/10.1105/tpc.108.058172

Saleh A, Alvarez-Venegas R, Yilmaz M, Oahn-Le HG, Sadder M, Al-Abdallat A, Xia Y, Lu G, Ladunga I, Avramova Z (2008) The highly similar Arabidopsis homologs of Trithorax ATX1 and ATX2 encode proteins with divergent biochemical functions. Plant Cell 20(3):568-579. https://doi.org/10.1105/tpc.1 07.056614

Shi J, Dong A, Shen WH (2015) Epigenetic regulation of rice flowering and reproduction. Front Plant Sci 5:803

Sui $P$, Jin J, Ye S, Mu C, Gao J, Feng H, Shen WH, Yu Y, Dong A (2012) H3K36 methylation is critical for brassinosteroid-regulated plant growth and development in rice. Plant J 70(2):340-347. https://doi.org/10.1111/j.1365-313 X.2011.04873.X

Sui P, Shi J, Gao X, Shen WH, Dong A (2013) H3K36 methylation is involved in promoting rice flowering. Mol Plant 6(3):975-977. https://doi.org/10.1093/ $\mathrm{mp} / \mathrm{sss} 152$

Sun C, Fang J, Zhao T, Xu B, Zhang F, Liu L, Tang J, Zhang G, Deng X, Chen F, Qian Q, Cao X, Chu C (2012) The histone methyltransferase SDG724 mediates $\mathrm{H} 3 \mathrm{~K} 36 \mathrm{me} 2 / 3$ deposition at MADS50 and RFT1 and promotes flowering in rice. Plant Cell 24(8):3235-3247. https://doi.org/10.1105/tpc.112.101436

Tamada Y, Yun JY, Woo S, Amasino RM (2009) ARABIDOPSIS TRITHORAX-RELATED7 is required for methylation of lysine 4 of histone $\mathrm{H} 3$ and for transcriptional activation of FLOWERING LOCUS C. Plant Cell 21(10):3257-3269. https://doi. org/10.1105/tpc.109.070060

Taoka K, Ohki I, Tsuji H, Furuita K, Hayashi K, Yanase T, Yamaguchi M, Nakashima C, Purwestri YA, Tamaki S, Ogaki Y, Shimada C, Nakagawa A, Kojima C, Shimamoto
K (2011) 14-3-3 proteins act as intracellular receptors for rice Hd3a florigen. Nature 476(7360):332-335. https://doi.org/10.1038/nature10272

Taoka K, Ohki I, Tsuji H, Kojima C, Shimamoto K (2013) Structure and function of florigen and the receptor complex. Trends Plant Sci 18(5):287-294. https:// doi.org/10.1016/j.tplants.2013.02.002

Thorstensen T, Grini PE, Aalen RB (2011) SET domain proteins in plant development. Biochim Biophys Acta 1809(8):407-420. https://doi.org/10.101 6/j.bbagrm.2011.05.008

Veiseth SV, Rahman MA, Yap KL, Fischer A, Egge-jacobsen W, Reuter G, Zhou MM, Aalen RB, Thorstensen T (2011) The SUVR4 histone lysine methyltransferase binds ubiquitin and converts $\mathrm{H} 3 \mathrm{~K} 9 \mathrm{me} 1$ to $\mathrm{H} 3 \mathrm{~K} 9 \mathrm{me} 3$ on transposon chromatin in Arabidopsis. PLoS Genet 7(3):e1001325. https://doi.org/10.1371/ journal.pgen.1001325

Wang J, Hu J, Qian Q, Xue HW (2013) LC2 and OsVIL2 promote rice flowering by photoperoid-induced epigenetic silencing of OsLF. Mol Plant 6(2):514-527. https://doi.org/10.1093/mp/sss096

Wei X, Xu J, Guo H, Jiang L, Chen S, Yu C, Zhou Z, Hu P, Zhai H, Wan J (2010) DTH8 suppresses flowering in rice, influencing plant height and yield potential simultaneously. Plant Physiol 153(4):1747-1758. https://doi.org/1 0.1104/pp.110.156943

Weng XY, Zhou SL, Zong W, Ouyang YD (2018) ChIP assay in rice. Bio 101: e1010135. https://doi.org/10.21769/BioProtoc.1010135 (in Chinese)

Wu W, Zheng X, Lu G, Zhong Z, Gao H, Chen L, Wu C, Wang HJ, Wang Q, Zhou K, Wang JL, Wu F, Zhang X, Guo X, Cheng Z, Lei C, Lin Q, Jiang L, Wang H, Ge S, Wan J (2013) Association of functional nucleotide polymorphisms at DTH2 with the northward expansion of rice cultivation in Asia. Proc Natl Acad Sci U S A 110(8):2775-2780. https://doi.org/10.1073/pnas.1213962110

Xue W, Xing Y, Weng X, Zhao Y, Tang W, Wang L, Zhou H, Yu S, Xu C, Li X, Zhang Q (2008) Natural variation in Ghd7 is an important regulator of heading date and yield potential in rice. Nat Genet 40(6):761-767. https://doi. org/10.1038/ng.143

Yang J, Lee S, Hang R, Kim SR, Lee YS, Cao X, Amasino R, An G (2013) OsVIL2 functions with PRC2 to induce flowering by repressing OsLFL1 in rice. Plant J 73(4):566-578. https://doi.org/10.1111/tpj.12057

Yano M, Katayose Y, Ashikari M, Yamanouchi U, Monna L, Fuse T, Baba T, Yamamoto K, Umehara Y, Nagamura Y, Sasaki (2000) Hd1, a major photoperiod sensitivity quantitative trait locus in rice, is closely related to the Arabidopsis flowering time gene CONSTANS. Plant Cell 12:2473-2483, 12, https://doi.org/10.1105/tpc.12.12.2473

Zhao Z, Yu Y, Meyer D, Wu C, Shen WH (2005) Prevention of early flowering by expression of FLOWERING LOCUS C requires methylation of histone H3 K36. Nat Cell Biol 7(12):1256-1260. https://doi.org/10.1038/ncb1329

Zheng T, Sun J, Zhou S, Chen S, Lu J, Cui S, Tian Y, Zhang H, Cai M, Zhu S, Wu M, Wang $Y$, Jiang L, Zhai H, Wang $H$, Wan J (2019) Post-transcriptional regulation of Ghd7 protein stability by phytochrome and OsGl in photoperiodic control of flowering in rice. New Phytol 224(1):306-320. https://doi.org/10.1111/nph.16010

\section{Publisher's Note}

Springer Nature remains neutral with regard to jurisdictional claims in published maps and institutional affiliations.

\section{Submit your manuscript to a SpringerOpen ${ }^{\circ}$ journal and benefit from:}

- Convenient online submission

- Rigorous peer review

- Open access: articles freely available online

- High visibility within the field

- Retaining the copyright to your article

Submit your next manuscript at $>$ springeropen.com 